\title{
Non specific pattern of lung function in a respiratory physiology unit: causes and prevalence: results of an observational cross-sectional and longitudinal study
}

\author{
Brigitte Chevalier-Bidaud', Karine Gillet-Juvin ${ }^{2,3}$, Etienne Callens², Romain Chenu', Sémia Graba²,
} Mohamed Essalhi ${ }^{2}$ and Christophe Delclaux ${ }^{2,4,5,6^{*}}$

\begin{abstract}
Background: ATS/ERS Task Force has highlighted that special attention must be paid when FEV 1 and FVC are concomitantly decreased $\left(<5^{\text {th }}\right.$ percentile) and the $\mathrm{FEV}_{1} / \mathrm{FVC}$ ratio is normal $\left(>5^{\text {th }}\right.$ percentile) because a possible cause of this non specific pattern (NSP) is collapse of small airways with normal TLC measured by body plethysmography $\left(>5^{\text {th }}\right.$ percentile). Our objectives were to determine the main lung diseases associated with this pattern recorded prospectively in a lung function testing (LFT) unit, the prevalence of this pattern in our LFT and among the diseases identified, and its development.

Methods: Observational study of routinely collected data selected from our Clinical Database Warehouse.

Results: The prevalence of NSP was 841/12 775 tests (6.6\%, 95\% Cl: 6.2 to 7.0\%). NSP was mainly associated with seven lung diseases: asthma (prevalence of NSP among asthmatics: 12.6\%), COPD/emphysema (prevalence 8.6\%), bronchiectasis (12.8\%), sarcoidosis (10.7\%), interstitial pneumonia (4.0\%), pulmonary hypertension (8.9\%) and bilateral lung transplantation for cystic fibrosis (36.0\%). LFT measurements were described in 185 patients with NSP and indisputable nonoverlapping causes. A moderate defect $\left(\mathrm{FEV}_{1}: 66 \pm 9 \%\right.$ predicted) with mild lung hyperinflation (FRC: $111 \pm 27 \%$, RV: $131 \pm 33 \%$ predicted: suggesting distal airway obstruction) was evidenced whatever the underlying cause. A long term stability of NSP was evidenced in 130/185 patients (70\% 95\% Cl: 64 to 77\%).
\end{abstract}

Conclusions: NSP is observed in asthma, COPD/emphysema, bronchiectasis, sarcoidosis, pulmonary hypertension, interstitial pneumonia and after bilateral lung transplantation and remains stable in the majority of patients.

Keywords: Asthma, Bronchiectasis, COPD, Emphysema, Pulmonary hypertension, Sarcoidosis, Small airway obstructive syndrome, Non specific pattern of lung function

\section{Background}

An obstructive ventilatory defect is a disproportionate reduction in maximal airflow from the lung in relation to the maximal volume (i.e. vital capacity, VC) that can be displaced from the lung [1]. It is defined by a reduced Forced Expiratory Volume in 1 second $\left(\mathrm{FEV}_{1}\right) / \mathrm{VC}$ ratio below the $5^{\text {th }}$ percentile of the predicted value. As stated

\footnotetext{
* Correspondence: christophe.delclaux@egp.aphp.fr

${ }^{2}$ AP-HP, Hôpital européen Georges-Pompidou, Service de Physiologie -

Clinique de la Dyspnée, 75015 Paris, France

${ }^{4}$ Sorbonne Paris Cité, Faculté de médecine, Université Paris Descartes, 75006 Paris, France

Full list of author information is available at the end of the article
}

by the ATS/ERS task force [1], "special attention must be paid when $\mathrm{FEV}_{1}$ and forced VC (FVC) are concomitantly decreased and the $\mathrm{FEV}_{1} / \mathrm{FVC}$ ratio is normal or almost normal [...]. A possible cause of this pattern is patchy collapse of small airways early in exhalation. Under these conditions, total lung capacity (TLC) may be normal, but residual volume (RV) is ordinarily increased. " This pattern has been named as small airways obstruction syndrome by Stanescu [2], and has initially been described in small series of adults with emphysema, small airways diseases, bronchial asthma [2] and also in asthmatic children [3]. Hyatt and colleagues identified more recently the 
medical conditions associated with this pattern from a database of lung function tests (LFT) results and medical records [4]. These authors showed that $68 \%$ of the patients were suffering from airway disease (including asthma, chronic obstructive pulmonary disease [COPD] and bronchiectasis), while the others suffered from restricted expansion of the thorax or the lung [4]. Consequently, they preferred to define this pattern as a non specific pattern (NSP).

The objective of our observational study using routinely collected data were to confirm the results of Hyatt and colleagues (main lung diseases associated with this syndrome), to further assess the prevalence of this syndrome in these diseases and to describe the follow-up of this NSP as done by the same research group [5]. These objectives have practical consequences for lung function testing units because if the prevalence of the syndrome is "significant" it is a plea for systematic absolute lung volume measurement when a reduction of $\mathrm{FEV}_{1}$ with a normal $\mathrm{FEV}_{1} / \mathrm{FVC}$ ratio is evidenced.

\section{Methods}

Reporting is in accordance with STROBE Statement (http://www.strobe-statement.org/). Unfortunately, the statements of the REporting of studies Conducted using Observational Routinely collected Data (RECORD, http://www.strobe-statement.org/) are not available.

\section{Design}

Since January 2007, explicit procedures for the interpretation of LFT using a standardised report based on interpretative strategies of the ATS/ERS task force, including NSP definition $\left(\mathrm{FEV}_{1}\right.$ and $\mathrm{FVC}<5^{\text {th }}$ percentile with $\mathrm{FEV}_{1}$ / $\mathrm{FVC}>5^{\text {th }}$ percentile and TLC measured by body plethysmography $>5^{\text {th }}$ percentile [1]), have been implemented in our unit. The physicians who are responsible for ordering tests have to state the clinical question to be answered and the physicians who are responsible for interpreting the results of LFT further ask patients why they were sent for testing, record ethnicity (mandatory), respiratory symptoms (including Medical Research Council [MRC] dyspnea score 1 to 5 , mandatory), as well as smoking status (mandatory), the type and dosage of any medication that may alter lung function (tests are performed while the patient takes his/ her usual treatment excepting methacholine challenge test), including when the drugs were last administered, and quality criteria of LFT in our database allowing a standardized LFT report (mandatory: see Figure 1).

Our first objective was to identify the main lung diseases associated with the recording of NSP. It has to be stated that a non reduced TLC measured by body plethysmography was an inclusion criterion according to guidelines [1]; thus patients with restricted expansion of the lung and the chest wall were not retrieved even if our clinical experience shows that some patients with interstitial pneumonia may exhibit a more significant reduction of $\mathrm{FEV}_{1}$ and FVC (as compared with TLC reduction) with normal $\mathrm{FEV}_{1} / \mathrm{FVC}$ (complex restrictive pattern [6]).

Due to the observational design of the study using routinely collected data only indisputable diagnoses were selected by the agreement between the diagnosis reported (1) by the LFT physician making the report (LFT Database), and (2) by the code in the Clinical Database Warehouse (CDW, including International Classification of Diseases [ICD-10, recorded by the staff of pulmonologists] and CCAM French public health insurance codes). Furthermore, the diagnoses were controlled for tobacco exposure. We thus selected patients (from January, 2007 to December, 2012) based on their smoking history: COPD were smokers $\geq 15$ pack-year (repeated LFT allowed to ensure conventional criteria of COPD, namely post-bronchodilator $\mathrm{FEV}_{1} / \mathrm{FVC}<70 \%$; emphysema, especially centrilobular, was deemed to be present in presence of associated hyperinflation [any increase in static lung volumes]), while other diagnoses were associated with a smoking history $<15$ pack-year. If the patient had undergone multiple LFT over this 6year period, we used only the measurements from their first visit for the cross-sectional assessment. Obviously, for COPD patients, NSP diagnosis is incompatible with COPD diagnosis since $\mathrm{FEV}_{1} / \mathrm{FVC}$ is $>70 \%$. Thus, only COPD patients with transient NSP were retrieved [5]. Finally patients with multiple lung disease diagnoses were excluded.

The second objective was to evaluate the prevalence of the NSP in our LFT unit and among the main lung diseases that have been identified, using the number of NSP over all tests recorded in the LFT database and the number of NSP in each lung disease over the number of patients with each disease having had LFT, respectively.

The third objective was to assess the long term followup of the patients exhibiting NSP.

The selection process is summarized in Figure 1, it satisfied to the following steps:

1. For the main objective (main lung diseases associated with NSP)

- extraction of all LFT recorded as NSP in the LFT database

- selection of the first LFT for each patient with NSP

- identification of main lung diseases associated with NSP (LFT database): recorded diagnosis for at least 5 patients (miscellaneous diseases were excluded, see Figure 1 legend)

- confirmation of the diagnosis by pulmonologists (ICD-10 database)

- selection of Caucasian subjects with NSP

- extraction of LFT raw data of patients with NSP 


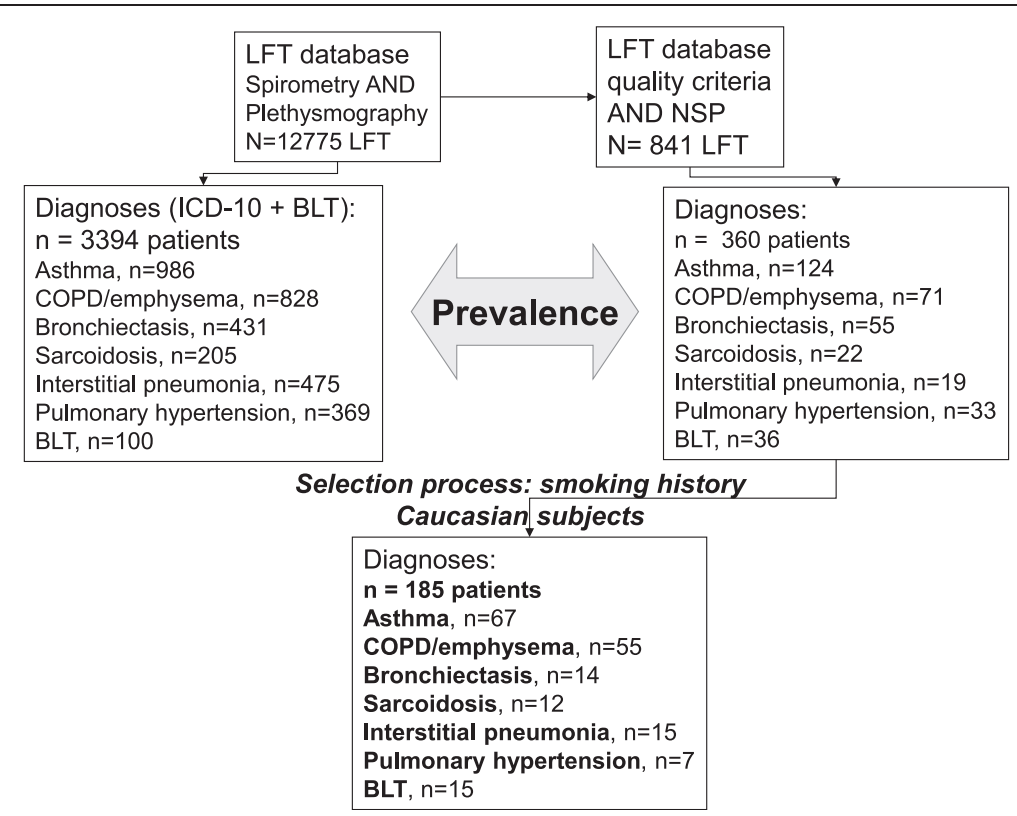

Figure 1 Selection of the patients and prevalence estimation. LFT: lung function tests; NSP: Non Specific Pattern; COPD: chronic obstructive pulmonary disease; BLT: bilateral lung transplantation (that was identified in the Clinical Database Warehouse by a specific CCAM code). PY: Pack-years for smoking history. The process of data selection is described in the Methods section. On the right side of the flow-chart diagram, the selection process of the 185 patients with NSP described in Table 2 is showed. The first step allowed the selection of patients instead of LFT (from 841 LFT to 360 patients): 30 patients with miscellaneous diseases (see Methods) were excluded, and 360 patients were selected (451 tests were follow-up LFT). All these 360 patients had the "NSP" diagnosis selected by the physician in charge of the medical report, based on the results of LFT showing the predicted value of each parameter and their $5^{\text {th }}$ percentile $\left(95^{\text {th }}\right.$ percentile for absolute lung volumes, additionally) based on normative equations for spirometry and lung volumes with correction for ethnicity $[13,14]$. Consequently, the prevalence of NSP in each lung disease was calculated from this sample. The next step was conducted to describe lung function test results from a highly selected subgroup with indisputable diagnoses. For the purpose of the study a more recent Caucasian set of predicted values for spirometry was used [12] allowing the calculation of Z-scores. After the exclusion of non Caucasian subjects and patients with a smoking history $\geq 15$ pack-year for non COPD/emphysema diagnoses, 185 / 360 patients were available for the final description.

- calculation of their percentages of predicted values and Z-scores (the normative equations used are for Caucasian subjects)

2. For the secondary objective (prevalence of NSP)

- number of patients with NSP over the number of patients with LFT including both spirometry and plethysmography (prevalence of NSP in our LFT, whatever the associated disease)

- number of patients with NSP and one specific lung disease over the number of patients with LFT (spirometry plus plethysmography) and this specific lung disease recorded in ICD-10 database (prevalence of NSP among each lung disease).

3. For the follow-up study

- patients with an NSP and at least one follow-up LFT 6 months or more after the initial assessment were identified and included in the follow-up study.

Lung function testing was done by four experienced pulmonary technologists. The tests included spirometry, body plethysmography with airway resistance (Raw using sRaw total [7]) and sometimes lung diffusion for carbon monoxide
(DLCO) measurements using an automated system (MasterScreen, Jaeger, CareFusion ${ }^{\circ}$ San Diego, California: two apparatus, unchanged over the sixyears of the survey) according to the ATS/ERS task force performed during the same visit [1,8-11]. After raw data extraction, predicted values of Caucasians were calculated for spirometry using Stanojevic and colleagues reference values [12], while values for slow $\mathrm{VC}, \mathrm{FEV}_{1}$ /slow $\mathrm{VC}$ and body plethysmography were those routinely used in our testing unit $[13,14]$.

This was an observational study in which informed consent was obtained from all subjects, and the database was declared to the French regulatory agency for computer data (Commission Nationale de l'Informatique et des Libertés, $n^{\circ} 1391593$ v0). Verbal consent was obtained according to the French Law, which was confirmed by The Institutional Review Board of the French learned society for respiratory medicine (SPLF: CEPRO 2013-010).

\section{Statistics}

Results are expressed as mean \pm SD or percentages with 95\% confidence interval $(\mathrm{CI})$ with the exception of MRC 
score. Comparison of TLC obtained by plethymography and alveolar volume (VA) obtained during DLCO measurement used the paired $t$ test. Comparisons used Kruskall Wallis test for continuous variables and chi-2 test for qualitative variables (see Table 1). A p value $<$ 0.05 was deemed significant.

\section{Results}

\section{Cross-sectional assessment}

During the six-year period (2007 to 2012), the Clinical Database Warehouse showed that 12775 LFT (spirometry and plethysmography) were performed and that a diagnosis of NSP was recorded for 841 LFT (6.6\%, 95\% CI: 6.2 to $7.0 \%$, after excluding LFT with insufficient quality criteria). The selection process is summarized in Figure 1.

Using ICD-10 and CCAM (for bilateral lung transplantation [BLT]) codes, the prevalence of NSP (341 patients) in each lung disease was estimated: asthma, 124/986 (12.6\%, 95\% CI: 10.5 to $14.6 \%)$, COPD/emphysema, $71 / 828(8.6 \%$, 95\% CI: 6.7 to $10.5 \%)$, bronchiectasis, $55 / 431$ (12.8\%, 95\% CI: 9.6 to $15.9 \%)$, sarcoidosis $22 / 205$ (10.7\%, 95\% CI: 6.5 to 15.0\%), interstitial pneumonia 19/475 (4.0\%, 95\% CI: 2.2 to $5.8 \%$ ), pulmonary hypertension, 33/369 (8.9\%, 95\% CI: 6.0 to $11.9 \%$ ) and BLT for cystic fibrosis, $36 / 100$ (36.0\%, 95\% CI: 26.5 to $45.5 \%)$.

The final selection of 185 Caucasian patients with NSP allowed the description of their characteristics in Tables 1 and 2. The results of the LFT demonstrated that a moderate mean obstructive defect was evidenced associated with mild air trapping. The degree of the obstructive defect was similar whatever the underlying disease whereas the degree of lung air trapping varied among diseases (Table 2). Asthmatics demonstrated the highest BMI values (Table 2), and 31/67 (46\%) patients were obese (BMI $\geq 30 \mathrm{~kg} \cdot \mathrm{m}^{-2}$ ).

Patients with pulmonary hypertension were classified according to the World Health Organization Groups of pulmonary hypertension [15] as: group $1, \mathrm{n}=3$; group 4, $\mathrm{n}=2$, group $5, \mathrm{n}=2$.

\section{Follow-up study}

Among the 841 LFT evidencing a NSP, 360 patients are described in Figure 1 while 30 additional patients were suffering from miscellaneous diseases (see Figure 1 legend). Thus the 451 remaining LFT were related to the patients having a NSP on recurrent tests. Among the 185 patients with indisputable diagnoses, the majority (130/185: 70\% 95\% CI: 64 to $77 \%$ ) demonstrated a stable pattern while 16 patients (9\%, 95\% CI: 5 to $13 \%$ ) showed a restrictive pattern (TLC $<5^{\text {th }}$ percentile, 12 patients with interstitial pneumonia and 4 with sarcoidosis) and 39 patients (21\%, 95\% CI: 15 to $27 \%$ ) showed an obstructive pattern $\left(\mathrm{FEV}_{1} / \mathrm{VC}<5^{\text {th }}\right.$ percentile, 10 patients with asthma and 29 with COPD/emphysema).
Table 1 Characteristics of the 185 patients with Non Specific Pattern of Lung Function

\begin{tabular}{|c|c|}
\hline $\begin{array}{l}\text { Characteristic } \\
\text { Mean } \pm \text { SD (except when stated) or } n\end{array}$ & $\begin{array}{l}185 \text { patients } \\
\text { with NSP }\end{array}$ \\
\hline Sex, Female/Male & $99 / 86$ \\
\hline Age, years & $57 \pm 19$ \\
\hline $\mathrm{BMI}, \mathrm{kg} \cdot \mathrm{m}^{-2}$ & $26.9 \pm 8.4$ \\
\hline $\mathrm{BMI} \geq 30 / 25$ to $30 /<25 \mathrm{~kg} \cdot \mathrm{m}^{-2}$ & $49 / 55 / 81$ \\
\hline \multicolumn{2}{|l|}{ Smoking history } \\
\hline Never smokers, $\mathrm{n}$ & 105 \\
\hline Ex-smokers, $n$ & 48 \\
\hline Current smokers, $\mathrm{n}$ & 32 \\
\hline Pack-year, median [interquartile] & $0[0 ; 35]$ \\
\hline MRC score, median [interquartile] & $2.0[1.0 ; 2.0]$ \\
\hline $\mathrm{FEV}_{1}, \mathrm{~L}$ & $1.96 \pm 0.68$ \\
\hline $\mathrm{FEV}_{1}, \%$ predicted $[12]$ & $66 \pm 9$ \\
\hline $\mathrm{FEV}_{1}, \mathrm{z}$-score & $-2.51 \pm 0.61$ \\
\hline FVC, L & $2.66 \pm 0.82$ \\
\hline FVC,\% predicted [12] & $67 \pm 9$ \\
\hline FVC, z-score & $-2.58 \pm 0.71$ \\
\hline $\mathrm{FEV}_{1} / \mathrm{FVC}$ & $0.77 \pm 0.08$ \\
\hline $\mathrm{FEV}_{1} / \mathrm{FVC}, \%$ predicted [12] & $99 \pm 9$ \\
\hline $\mathrm{FEV}_{1} / \mathrm{FVC}, \mathrm{z}$-score & $-0.24 \pm 0.98$ \\
\hline Slow inspiratory VC, L & $2.71 \pm 0.79$ \\
\hline Slow inspiratory VC,\% predicted [13] & $76 \pm 11$ \\
\hline $\mathrm{FEV}_{1} /$ Slow inspiratory VC & $0.75 \pm 0.08$ \\
\hline $\mathrm{FEV}_{1} /$ Slow inspiratory $\mathrm{VC}, 5^{\text {th }}$ percentile [13] & $0.68 \pm 0.04$ \\
\hline TLC, L & $5.49 \pm 1.19$ \\
\hline TLC,\% predicted [14] & $96 \pm 12$ \\
\hline TLC, $5^{\text {th }}$ percentile & $4.66 \pm 1.07$ \\
\hline FRC, L & $3.46 \pm 0.92$ \\
\hline FRC,\% predicted [14] & $111 \pm 27$ \\
\hline$R V, L$ & $2.68 \pm 0.85$ \\
\hline $\mathrm{RV}, \%$ predicted [14] & $131 \pm 33$ \\
\hline $\operatorname{Raw}_{\text {tot }}, \mathrm{kPa} \cdot \mathrm{S}^{-1}$ & $0.46 \pm 0.28$ \\
\hline Raw $_{\text {tot, }} \%$ predicted & $154 \pm 99$ \\
\hline Specific Raw tot, KPa.s & $1.60 \pm 0.98$ \\
\hline Specific Raw $_{\text {tot }} \%$ predicted & $166 \pm 101$ \\
\hline VA, L (n patients with measurement)* & $4.01 \pm 0.90(62)$ \\
\hline VA/TLC (n patients with measurement) & $0.75 \pm 0.12(62)$ \\
\hline
\end{tabular}

Set of predicted values are quoted in the first column.

*: among these 62 patients, $53(85 \%)$ depicted a restrictive defect defined by VA below the $5^{\text {th }}$ percentile value of TLC minus $150 \mathrm{~mL}$

\section{Discussion}

In the presence of a normal TLC, a decrease in VC, and therefore of $\mathrm{FEV}_{1}$, is the consequence of an increase in RV. Pathologic conditions associated with intrinsic and 
Table 2 Main characteristics of the patients with NSP according to underlying condition

\begin{tabular}{|c|c|c|c|c|c|c|c|c|}
\hline $\begin{array}{l}\text { Characteristic } \\
\text { Mean } \pm \text { SD (except }\end{array}$ & Asthma & $\begin{array}{c}\text { COPD/ } \\
\text { emphysema }\end{array}$ & Bronchiectasis & Sarcoidosis & $\begin{array}{l}\text { Interstitial } \\
\text { pneumonia }\end{array}$ & $\begin{array}{c}\text { Pulmonary } \\
\text { hypertension }\end{array}$ & $\begin{array}{l}\text { Bilateral lung } \\
\text { transplantation }\end{array}$ & $P$ value \\
\hline when stated) or $n$ & $N=67$ & $\mathrm{~N}=55$ & $N=14$ & $\mathrm{~N}=12$ & $N=15$ & $N=7$ & $N=15$ & \\
\hline Sex, F/M & $48 / 19$ & $17 / 38$ & $12 / 2$ & $7 / 5$ & $6 / 9$ & $5 / 2$ & $4 / 11$ & $<0.0001$ \\
\hline Age, years & $51 \pm 15$ & $64 \pm 10$ & $60 \pm 16$ & $47 \pm 15$ & $66 \pm 14$ & $47 \pm 17$ & $28 \pm 9$ & $<0.0001$ \\
\hline $\mathrm{BMI}, \mathrm{kg} \cdot \mathrm{m}^{-2}$ & $30.6 \pm 9.3$ & $26.7 \pm 6.2$ & $21.1 \pm 2.4$ & $27.3 \pm 5.3$ & $28.1 \pm 5.9$ & $22.4 \pm 4.6$ & $17.7 \pm 1.6$ & $<0.0001$ \\
\hline Smoking history & & & & & & & & $<0.0001$ \\
\hline Never smokers, $\mathrm{n}$ & 54 & 0 & 11 & 9 & 10 & 6 & 15 & \\
\hline Ex-smokers, $n$ & 6 & 31 & 2 & 3 & 5 & 1 & 0 & \\
\hline Current smokers, $\mathrm{n}$ & 7 & 24 & 1 & 0 & 0 & 0 & 0 & \\
\hline Pack-year, median $[\mathrm{IQ}]$ & $0[0-0]$ & $45[36-59]$ & $0[0-0]$ & $0[0-4]$ & $0[0-3]$ & $0[0-0]$ & $0[0-0]$ & $<0.0001$ \\
\hline MRC score, median [IQ] & $2[1-2]$ & $2[1-2]$ & $1[1-2]$ & $2[2-2]$ & $2[2-2]$ & $2[1-5]$ & $1[1-1]$ & 0.0003 \\
\hline $\mathrm{FEV}_{1}, \%$ predicted & $64 \pm 7$ & $63 \pm 8$ & $61 \pm 9$ & $67 \pm 8$ & $69 \pm 8$ & $59 \pm 5$ & $66 \pm 8$ & 0.118 \\
\hline FVC, \% predicted & $65 \pm 8$ & $65 \pm 9$ & $63 \pm 9$ & $70 \pm 10$ & $68 \pm 9$ & $63 \pm 5$ & $66 \pm 9$ & 0.239 \\
\hline $\mathrm{FEV}_{1} / \mathrm{FVC}, \%$ predicted & $97 \pm 8$ & $96 \pm 7$ & $96 \pm 7$ & $95 \pm 6$ & $99 \pm 10$ & $93 \pm 5$ & $100 \pm 8$ & 0.321 \\
\hline TLC,\% predicted & $94 \pm 10$ & $99 \pm 14$ & $96 \pm 8$ & $90 \pm 7$ & $90 \pm 9$ & $96 \pm 15$ & $93 \pm 6$ & 0.189 \\
\hline FRC, $\%$ predicted & $102 \pm 27$ & $121 \pm 26$ & $116 \pm 21$ & $97 \pm 14$ & $96 \pm 16$ & $111 \pm 35$ & $127 \pm 11$ & $<0.0001$ \\
\hline $\mathrm{RV}, \%$ predicted & $132 \pm 33$ & $145 \pm 33$ & $136 \pm 22$ & $119 \pm 21$ & $110 \pm 25$ & $136 \pm 30$ & $169 \pm 28$ & $<0.0001$ \\
\hline
\end{tabular}

IQ denotes interquartile.

extrinsic obstruction of small airways, together with expiratory muscle weakness, will lead to an increased RV. Dynamic expiratory airflow obstruction could also produce an increase in RV and a decrease in FVC. However, measuring a slow VC instead of a forced one would avoid the rise in RV, which was not observed in our study. Consequently, the pattern of NSP may effectively be related to patchy collapse of small airways early in exhalation, and does not seem to be related to a bronchoconstrictor effect of deep inspiration [16] that would be associated with normal slow inspiratory vital capacity.

To our best knowledge, only one study evaluated the main lung diseases that are associated with this pattern [4]. In the retrospective study of Hyatt and colleagues, NSP was observed in 7702/80 929 subjects (9.5\%), and a random sample of 100 patients allowed to define the medical conditions associated with this pattern [4]. The authors showed that 52 patients had some degree of airway responsiveness (positive response to bronchodilator or methacholine) including 26 asthmatics, 16 were suffering from chronic lung disease (including 11 with COPD and 3 with bronchiectasis), 7 were obese only and 25 were suffering from various conditions (prevalence $\leq 5 \%$ for each condition). Overall, in their study, obesity $\left(B M I \geq 30 \mathrm{~kg} / \mathrm{m}^{2}\right)$ was very prevalent $(50$ subjects equally distributed between the sexes) and they highlighted the association of NSP with obesity and hyperresponsiveness (31\%). Obesity has also been associated with propensity of distal airway closure/hyperresponsiveness [17]. We similarly observed that asthmatic patients in our series were often obese, even if obesity prevalence was lower in our series (26\%), which may further explain our lower prevalence of NSP. These authors emphasized that some patients had no evidence of airway disease. Restricted expansion of the thorax or lung may have explained the NSP in most of these subjects since the conditions were suggestive of restriction despite the low normal TLC. Interestingly, some of these conditions have also been associated with increased airway responsiveness [18,19], which may have favoured the occurrence of this NSP.

Our design had both similarities and differences. Large databases were used in the two studies that used body plethysmography for absolute lung volumes measurements. We deliberately decided not to include all medical conditions associated with NSP (30 patients were excluded) because one objective was to provide confident prevalences of the functional pattern in the various medical conditions. The prevalence of NSP was thus described for seven conditions associated with the pattern, over 360 patients. Then we further selected 185 patients in order to describe the functional abnormalities and to evaluate whether the severity of the pattern varied among the seven conditions. To this end, we selected only Caucasian (to use only one set of predicted values) and non or light smokers in non COPD/emphysema conditions (to exclude overlapping conditions). In agreement with the study of Hyatt and colleagues, a moderate impairment was evidenced $\left(\mathrm{FEV}_{1} 68 \pm 9 \%\right.$ predicted in their study) [4]. 
A large series of patients has been obtained with indisputable diagnoses and, besides lung diseases already associated with NSP [4], we further show that some conditions as interstitial pneumonia, pulmonary hypertension or bilateral lung transplantation are associated with low to moderate prevalence of the syndrome. Interestingly, in patients with bronchiolitis obliterans syndrome after allogeneic hematopoietic stem cell transplantation [20], Bergeron and colleagues identified two functional phenotypes: a typical obstructive lung defect and an atypical obstructive lung defect with a concomitant decrease in the $\mathrm{FEV}_{1}$ and FVC with a normal total lung capacity (31\% of the patients, 95\% CI: 21 to $42 \%)$. Consequently, this latter prevalence is similar to ours, and one may hypothesize that this high prevalence is specifically related to obliterative bronchiolitis [21] rather than to biases related to the presence of lung size mismatching between donor and recipient, and/or inaccurate predicted values for donor lungs.

Before the more recent ATS/ERS Task Force recommendations [1], previous international guidelines did not formally classified this functional phenotype as an obstructive defect, as pointed out by Stanescu [2]. In patients with established airway diseases, as COPD or asthma, a reduction in $\mathrm{FEV}_{1}$ would be regarded by most physicians as indicative of airway obstruction whatever the FVC value. On the other hand, when the diagnosis has not been established or in presence of a patient with pulmonary hypertension, a "restrictive" pattern observed after the sole spirometry may lead to misdiagnosis, accordingly with the low predictive value of spirometry for lung restriction [22]. Furthermore, measurement of absolute volumes by dilution technique may lead to misdiagnosis (restrictive pattern), as suggested by the reduction of alveolar volume as compared to TLC, which would lead to restrictive defect diagnosis in $85 \%$ of the patients (see Table 1 ).

Some authors prefer to label this pattern as non specific due to the normalcy of the $\mathrm{FEV}_{1} / \mathrm{VC}$ ratio and of the TLC $[4,5]$. Nevertheless, it has to be emphasized that small airway (bronchiolar) involvement is a characteristic or can occur in all these diseases. For instance in pulmonary hypertension, a mild obstructive pattern is welldescribed that can be associated with exercise-induced dynamic hyperinflation [23]. Small airway disease is also well demonstrated in interstitial pneumonias [24], suggesting a mixed defect when an additional restrictive defect occurs as observed in our study. The mild to moderate lung air trapping that was evidenced in our study together with an increase in airway resistance further suggest distal airway obstruction. Along this line we showed that both airway resistance and specific airway resistance can augment in the presence of peripheral airway obstruction $[25,26]$.
Finally, the observed prevalence of this syndrome in selected conditions may seem relatively high, but we previously demonstrated that isolated hyperinflation is not infrequent in asthmatic children (7-11\%) [3]. Logically, due to this prevalence in common respiratory diseases, the overall prevalence in our LFT unit (6.6\%) is in agreement with the results of Hyatt and colleagues (9.5\%) and with those of Aaron and colleagues (15\%, 95\% CI: 13 to $17 \%$ patients with low FVC and normal absolute lung volumes) [22]. Unfortunately, the diagnoses associated with this specific functional pattern were not described in this latter study [22].

Our study has inherent limitations due to its design. Data extraction was based on the actual recording of NSP by the physician in charge of the LFT report made in the routine practice; consequently, the observed prevalences could have been underestimated. These prevalences are only indicative because some patients had several LFT that may have facilitated the detection of NSP, which can be a transient functional phenotype [5]. Reversibility of airway limitation was not systematically assessed because patients are tested while taking their usual respiratory treatment. Finally, our study was not designed to evaluate all lung diseases associated with NSP, since only concordant and indisputable diagnoses were retrieved for functional description. Whether NSP is associated with specific clinical phenotypes warrants further studies.

\section{Conclusion}

In conclusion, NSP can be observed in asthma, COPD/ emphysema, bronchiectasis, sarcoidosis, interstitial pneumonias, pulmonary hypertension and after bilateral lung transplantation. Thus, the measurement of static lung volumes by body plethysmography can be helpful in presence of $\mathrm{FEV}_{1}$ and $\mathrm{FVC}$ reduction, depending on previous measurements, lung imaging, and clinical judgment.

\section{Competing interests}

The authors declare no personal or financial support or author involvement with organization(s) with financial interest in the subject matter or any actual or potential conflict of interest.

\section{Authors' contributions}

All authors made 1) substantial contributions to conception and design (KGJ, $E C, M E, S G, C D 2)$, acquisition of data (KGJ, EC, ME, SG), or analysis (BCB, RC, $\mathrm{CD} 2)$ and interpretation of data (all authors); 2) drafting the article (BCB, CD2) or revising it critically for important intellectual content (KGJ, EC, ME, SG, RC); and 3) final approval of the version to be published (all authors). CD2 is the guarantor of the entire manuscript.

\section{Acknowledgments}

The authors thank the Dr Paul Avillach (Department of medical informatics) for providing the access to the Clinical Database Warehouse, and the technicians of the pulmonary function laboratory for their expert assistance (Martine Riquelme, Françoise Genisty, Mireille Morot, Marien Bokouabassa).

Brigitte Chevalier-Bidaud was supported by a grant from CARDIF - I'Assistance Respiratoire (director Dr Fayssal El Husseini). 


\section{Funding}

This study was not funded.

\section{Author details}

'AP-HP, Hôpital européen Georges-Pompidou, Unité d'Épidémiologie et de Recherche Clinique, 75015 Paris, France. ${ }^{2}$ AP-HP. Hôpital européen Georges-Pompidou, Service de Physiologie - Clinique de la Dyspnée, 75015 Paris, France. ${ }^{3} \mathrm{AP}-\mathrm{HP}$, Hôpital européen Georges-Pompidou, Service de Pneumologie, 75015 Paris, France. ${ }^{4}$ Sorbonne Paris Cité, Faculté de médecine, Université Paris Descartes, 75006 Paris, France. ${ }^{5}$ Sorbonne Paris Cité, Université Paris Descartes, EA2511, 75014 Paris, France. ${ }^{6} \mathrm{ClC} 9201$

Plurithématique, Hôpital Européen Georges Pompidou, 75015 Paris, France.

Received: 15 April 2014 Accepted: 17 September 2014

Published: 19 September 2014

\section{References}

1. Pellegrino R, Viegi G, Brusasco V, Crapo RO, Burgos F, Casaburi R, Coates A, van der Grinten CP, Gustafsson P, Hankinson J, Jensen R, Johnson DC, MacIntyre N, McKay R, Miller MR, Navajas D, Pedersen OF, Wanger J: Interpretative strategies for lung function tests. Eur Respir J 2005, 26(5):948-968

2. Stanescu D: Small airways obstruction syndrome. Chest 1999, 116(1):231-233.

3. Mahut B, Bokov P, Delclaux C: Abnormalities of plethysmographic lung volumes in asthmatic children. Respir Med 2010, 104(7):966-971.

4. Hyatt RE, Cowl CT, Bjoraker JA, Scanlon PD: Conditions associated with an abnormal nonspecific pattern of pulmonary function tests. Chest 2009 135(2):419-424.

5. lyer VN, Schroeder DR, Parker KO, Hyatt RE, Scanlon PD: The nonspecific pulmonary function test: longitudinal follow-up and outcomes. Chest 2011, 139(4):878-886.

6. Dykstra BL, Reddy RS, Parker KO, lyer VN, Scanlon PD: The 'Complex Restrictive' PFT pattern: clinical and radiological analysis of a novel restrictive PFT pattern. Am J Respir Crit Care Med 2014, 189:A3540.

7. Mahut B, Caumont-Prim A, Plantier L, Gillet-Juvin K, Callens E, Sanchez O, Chevalier-Bidaud B, Bokov P, Delclaux C: Relationships between respiratory and airway resistances and activity-related dyspnea in patients with chronic obstructive pulmonary disease. Int I Chron Obstruct Pulmon Dis 2012, 7:165-171.

8. Macintyre N, Crapo RO, Viegi G, Johnson DC, van der Grinten CP, Brusasco V, Burgos F, Casaburi R, Coates A, Enright P, Gustafsson P, Hankinson J, Jensen R, McKay R, Miller MR, Navajas D, Pedersen OF, Pellegrino R, Wanger $\mathrm{J}$ : Standardisation of the single-breath determination of carbon monoxide uptake in the lung. Eur Respir J 2005, 26(4):720-735.

9. Miller MR, Crapo R, Hankinson J, Brusasco V, Burgos F, Casaburi R, Coates A, Enright $P$, van der Grinten $C P$, Gustafsson P, Jensen R, Johnson DC, MacIntyre N, McKay R, Navajas D, Pedersen OF, Pellegrino R, Viegi G, Wanger J, ATS/ERS Task Force: General considerations for lung function testing. Eur Respir J 2005, 26(1):153-161.

10. Miller MR, Hankinson J, Brusasco V, Burgos F, Casaburi R, Coates A, Crapo R, Enright $P$, van der Grinten $C P$, Gustafsson $P$, Jensen $R$, Johnson DC, Maclntyre N, McKay R, Navajas D, Pedersen OF, Pellegrino R, Viegi G, Wanger J, ATS/ERS Task Force: Standardisation of spirometry. Eur Respir J 2005, 26(2):319-338.

11. Wanger J, Clausen JL, Coates A, Pedersen OF, Brusasco V, Burgos F, Casaburi R, Crapo R, Enright P, van der Grinten CP, Gustafsson P, Hankinson J, Jensen R, Johnson D, Macintyre N, McKay R, Miller MR, Navajas D, Pellegrino R, Viegi $\mathrm{G}$ : Standardisation of the measurement of lung volumes. Eur Respir J 2005, 26(3):511-522

12. Stanojevic S, Wade A, Stocks J, Hankinson J, Coates AL, Pan H, Rosenthal M, Corey M, Lebecque $\mathrm{P}$, Cole TJ: Reference ranges for spirometry across all ages: a new approach. Am J Respir Crit Care Med 2008, 177(3):253-260.

13. Quanjer PH, Tammeling GJ, Cotes JE, Pedersen OF, Peslin R, Yernault JC: Lung volumes and forced ventilatory flows. Report working party standardization of lung function tests, European community for steel and coal. Official statement of the European respiratory society. Eur Respir J Suppl 1993, 16:5-40.

14. Stocks J, Quanjer PH: Reference values for residual volume, functional residual capacity and total lung capacity. ATS workshop on lung volume measurements. Official Statement of The European Respiratory Society. Eur Respir J 1995, 8(3):492-506.
15. Simonneau G, Robbins IM, Beghetti M, Channick RN, Delcroix M, Denton $C P$, Elliott CG, Gaine SP, Gladwin MT, Jing ZC, Krowka MJ, Langleben D, Nakanishi N, Souza R: Updated clinical classification of pulmonary hypertension. J Am Coll Cardiol 2009, 54(1 Suppl):S43-S54.

16. Delclaux C, Zerah-Lancner F, Mahut B, Ribeil S, Dubois A, Larger C, Harf A: Alveolar nitric oxide and effect of deep inspiration during methacholine challenge. Chest 2005, 127(5):1696-1702.

17. Essalhi M, Gillaizeau F, Chevallier JM, Ducloux R, Chevalier-Bidaud B, Callens E, Graba S, Gillet-Juvin K, Altman JJ, Louis B, Mahut B, Delclaux C: Risk factors for airway hyperresponsiveness in severely obese women. Respir Physiol Neurobiol 2013, 186(2):137-145.

18. Torchio R, Gulotta C, Ciacco C, Perboni A, Guglielmo M, Crosa F, Zerbini M, Brusasco V, Hyatt RE, Pellegrino R: Effects of chest wall strapping on mechanical response to methacholine in humans. J Appl Physiol 2006, 101(2):430-438

19. Dicpinigaitis PV, Spungen AM, Bauman WA, Absgarten A, Almenoff PL: Bronchial hyperresponsiveness after cervical spinal cord injury. Chest 1994, 105(4):1073-1076

20. Bergeron A, Godet C, Chevret S, Lorillon G, Peffault de Latour R, de Revel T, Robin M, Ribaud P, Socie G, Tazi A: Bronchiolitis obliterans syndrome after allogeneic hematopoietic SCT: phenotypes and prognosis. Bone Marrow Transplant 2013, 48(6):819-824.

21. Barker AF, Bergeron A, Rom WN, Hertz MI: Obliterative bronchiolitis. N Engl J Med 2014, 370(19):1820-1828.

22. Aaron SD, Dales RE, Cardinal P: How accurate is spirometry at predicting restrictive pulmonary impairment? Chest 1999, 115(3):869-873.

23. Laveneziana P, Garcia G, Joureau B, Nicolas-Jilwan F, Brahimi T, Laviolette L, Sitbon O, Simonneau G, Humbert M, Similowski T: Dynamic respiratory mechanics and exertional dyspnoea in pulmonary arterial hypertension. Eur Respir J 2013, 41(3):578-587.

24. Ryu JH: Classification and approach to bronchiolar diseases. Curr Opin Pulm Med 2006, 12(2):145-151.

25. Bokov P, Mauroy B, Mahut B, Delclaux C, Flaud P: Homothety ratio of airway diameters and site of airway resistance in healthy and COPD subjects. Respir Physiol Neurobiol 2014, 191:38-43.

26. Mahut B, Trinquart L, Bokov P, Le Bourgeois M, Waernessyckle S, Peiffer C, Delclaux C: Relationships between specific airway resistance and forced expiratory flows in asthmatic children. PLoS One 2009, 4(4):e5270.

doi:10.1186/1471-2466-14-148

Cite this article as: Chevalier-Bidaud et al:: Non specific pattern of lung function in a respiratory physiology unit: causes and prevalence: results of an observational cross-sectional and longitudinal study. BMC Pulmonary Medicine 2014 14:148.

\section{Submit your next manuscript to BioMed Central and take full advantage of:}

- Convenient online submission

- Thorough peer review

- No space constraints or color figure charges

- Immediate publication on acceptance

- Inclusion in PubMed, CAS, Scopus and Google Scholar

- Research which is freely available for redistribution

Submit your manuscript at www.biomedcentral.com/submit
C Biomed Central 